\title{
Ação da dopamina na secreção do hormônio do crescimento em novilhas pré-púberes da raça Nelore
}

\author{
Dopamine action in prepubertal Nelore heifers growth \\ hormone secretion
}

\author{
Emiliana Oliveira Santana Batista ${ }^{1 *}$; Daniel Cardoso ${ }^{2}$; Guilherme Paula Nogueira ${ }^{3}$
}

\section{Resumo}

O objetivo deste trabalho foi investigar o papel da dopamina na regulação da secreção do hormônio do crescimento $(\mathrm{GH})$ durante a maturação sexual em novilhas da raça Nelore. Os animais foram distribuídos de forma aleatória em dois grupos: Grupo sulpiride (antagonista dopaminérgico; 0,59 mg/ $\mathrm{kg}$, S.C.) e grupo controle (solução salina S.C.) aos 8, 12 e 16 meses de idade. Amostras de sangue foram colhidas a cada $15 \mathrm{~min}$ por $10 \mathrm{~h}$ após a administração das soluções. A quantificação hormonal foi realizada por radioimunoensaio. O coeficiente de variação inter-ensaio, intraensaio e a sensibilidade dos ensaios de GH foram, respectivamente: $17 \%, 15 \%$ e $0,25 \mathrm{ng} / \mathrm{mL}$. O tratamento com sulpiride aumentou a concentração média de $\mathrm{GH}$ aos 8 meses $(10,10 \pm 0,38 \mathrm{ng} / \mathrm{mL}$ vs $4,3 \pm 0,34 \mathrm{ng} / \mathrm{mL} ; \mathrm{P} \leq 0,05)$ e 12 meses de idade $(9,46 \pm 0,35 \mathrm{ng} / \mathrm{mL}$ vs $3,74 \pm 0,19 \mathrm{ng} / \mathrm{mL} ; \mathrm{P} \leq 0,05)$. Dentro do grupo sulpiride a concentração média de GH foi maior aos 8 e 12 meses comparada aos 16 meses de idade $(10,10 \pm 0,38$ $\mathrm{ng} / \mathrm{mL}$ vs $9,46 \pm 0,35 \mathrm{ng} / \mathrm{mL}$ vs $4,87 \pm 0,35 \mathrm{ng} / \mathrm{mL} ; \mathrm{P} \leq 0,05)$. Não houve diferença entre os grupos ( $\mathrm{P}$ $\geq 0,05$ ) em relação à área total de secreção de $\mathrm{GH}$, área total de picos, amplitude máxima dos picos de GH. Os resultados sugerem que a dopamina tem efeito inibitório sobre a secreção de GH, decrescendo em função da idade nas novilhas pré-púberes da raça Nelore.

Palavras-chave: Bos indicus, hipotálamo, puberdade, sulpiride

\begin{abstract}
The aim of this study was to evaluate the response of dopamine in the growth hormone secretion (GH) during Nellore heifer's sexual maturation. The animals were randomly assigned into two experimental groups: Sulpiride group (dopamine $\mathrm{D}_{2}$ antagonist, $0.59 \mathrm{mg} / \mathrm{kg}$, S.C.) and control group (saline solution S.C.) at 8, 12 and 16 months of age. Blood samples were collected every $15 \mathrm{~min}$ for $10 \mathrm{~h}$ after drug injection. Growth hormone was quantified by RIA, sensitivity $(0.25 \mathrm{ng} / \mathrm{mL})$ and intra and inter-assay variation coefficients were $15 \%$ and $17 \%$, respectively. GH concentration was higher in sulpiride group than control group at $8 \mathrm{mo}(10.1 \pm 0.38 \mathrm{ng} / \mathrm{mL}$ vs $4.3 \pm 0.34 \mathrm{ng} / \mathrm{mL} ; \mathrm{P}<0.05)$ and $12 \mathrm{mo}$ of age $(9.46 \pm$ 0.35 vs $3.74 \pm 0.19 \mathrm{ng} / \mathrm{mL} ; \mathrm{P}<0.05)$. In sulpiride group $\mathrm{GH}$ average concentration was greater at 8 and $12 \mathrm{mo}$ compared to $16 \mathrm{mo}$ of age $(10.10 \pm 0.38 \mathrm{ng} / \mathrm{mL}$ and $9.46 \pm 0.35 \mathrm{ng} / \mathrm{mL}$ vs $4.87 \pm 0.35 \mathrm{ng} / \mathrm{mL} ; \mathrm{P}$ $<0.05)$ respectively. There was no difference between groups $(\mathrm{P}>0.05)$ in total $\mathrm{GH}$ secretion area, total peak area and maximum peak amplitude. These results suggested an inhibitory dopamine effect on GH secretion in pre-pubertal Nellore heifers that decreases according to age.
\end{abstract}

Key words: Bos indicus, hypothalamus, puberty, sulpiride

${ }^{1}$ Discente, Universidade do Estado de São Paulo, USP, São Paulo, SP. E-mail: emilianamili@hotmail.com

2 Pesquisador, Agência Paulista de Tecnologia dos Agronegócios, APTA, Andradina, SP. E-mail: danielcardoso@apta.sp.gov.br

${ }^{3}$ Prof. da Universidade Estadual Paulista Júlio de Mesquita Filho, UNESP, Araçatuba, SP. E-mail: gpn@fmva.unesp.br

* Autor para correspondência 


\section{Introdução}

A idade a puberdade tem efeito impactante na eficiência reprodutiva e produtiva em bovinos de corte e leite (SANTOS et al., 2006). Melhoria genética e nutricional visando redução da idade à puberdade contribui para o aumento na vida reprodutiva e a produção de maior número de bezerros ao longo da vida reprodutiva da fêmea, com benefícios para toda a cadeia produtiva (CARDOSO; NOGUEIRA, 2007). Desta forma, além da implementação de boas práticas de manejo para melhoria do sistema de produção, é importante conhecer os processos fisiológicos que controlam a primeira ovulação (PATTERSON; WOOD; RANDLE, 2006).

A idade à primeira ovulação e a funcionalidade reprodutiva de uma fêmea apresenta ligação direta com aspectos relacionados à condição nutricional, condição corporal, fatores endócrinos, neuroendócrinos e suas inter-relações. A forma exata como esta relação é estabelecida ainda não está elucidada (CHEUNG et al., 1997, MONTEIRO et al., 2013). Chagas et al. (2007) indicaram a importância da ligação entre o fluxo de nutrientes com o eixo gonadotrófico e somatotrófico. O hormônio do crescimento (GH), a insulina, fatores de crescimento do tipo insulina (IGFs) e leptina têm papel importante em integrar as funções de lactação, nutrição e reprodução (CHAGAS et al., 2007, CHELIKANI et al., 2009).

Mudanças na concentração média e amplitude dos pulsos de GH foram observadas no período prépúbere em novilhas, sugerindo participação do $\mathrm{GH}$ no desenvolvimento puberal (YELICH et al., 1996).

Um dos mecanismos pelo qual o $\mathrm{GH}$ parece participar do processo de maturação que permite que ocorra a puberdade é por aumentar a sensibilidade ovariana às gonadotrofinas (ADVIS; WHITE SMITH; OJEDA, 1981).

Durante a maturação sexual na novilha, além das modificações na sensibilidade do hipotálamo ao estradiol, ocorrem alterações nas respostas a neurotransmissores excitatórios e inibitórios em função da idade e da disponibilidade de energia no meio interno (RAWLINGS et al., 2003). Em novilhas da raça Nelore houve diminuição da sensibilidade hipotalâmica a esteroides gonadais durante o processo de maturação sexual e participação de neurotransmissores alfa - adrenérgicos na secreção de LH (CARDOSO; NOGUEIRA, 2008). O conhecimento dos mecanismos neuroendócrinos envolvidos na maturação sexual de novilhas Nelore possibilita intervir no processo e antecipar a idade à primeira ovulação destes animais.

O objetivo deste estudo foi avaliar a concentração de GH em resposta ao uso de um antagonista dopaminérgico em novilhas pré-púberes da raça Nelore. Admitiu-se a hipótese de que a secreção de $\mathrm{GH}$ é inibida pela dopamina.

\section{Material e Métodos}

Foram utilizadas 10 novilhas da raça Nelore, oriundas de um rebanho comercial. Após o desmame (seis meses de idade, peso vivo médio de $130 \mathrm{~kg}$ ), estas foram levadas para o Campus da Universidade Estadual Paulista "Júlio de Mesquita Filho" (UNESP), localizada na cidade de Araçatuba, Estado de São Paulo (latitude $21^{\circ} 12$ ' 32" sul e longitude $50^{\circ} 25^{\prime} 58^{\prime \prime}$ oeste). As novilhas foram mantidas em piquetes de capim Tanzânia (Panicum maximum, Jacq.cv. Tanzânia I), recebendo suplementação com bagaço de cana hidrolisado, concentrado (milho, soja e núcleo) e com livre acesso a sal mineral e água. As novilhas foram distribuídas em dois grupos, sendo: a) CONTROLE (C): que receberam solução salina, S.C. (mesmo volume em que era administrado sulpiride), aos $8(\mathrm{n}=5), 12(\mathrm{n}=5)$ e 16 meses de idade $(n=4)$ b) SULPIRIDE $(S)$ : novilhas tratadas com sulpiride, antagonista de receptor (D2) dopaminérgico (Sigma-Aldrich, CO. St. Louis, MO, US, S8010); 0,59 mg/kg, S.C., aos $8(n=4), 12(n=5)$ e 16 meses de idade $(n=4)$. Amostras de sangue foram colhidas a cada $15 \mathrm{~min}$ por $10 \mathrm{~h}$ após a administração de sulpiride ou salina (HONARAMOOZ et al., 2000). 
No dia anterior à administração do sulpiride, a jugular das novilhas foi canulada, para permitir a coleta seriada de sangue. Para isto, procedeu-se a tranquilização com a associação de acepromazina $(0,02 \mathrm{mg} / \mathrm{kg})$ e xilazina $(0,5 \mathrm{mg} / \mathrm{kg})$ por via intramuscular (AGUIAR, 2004), tricotomia e assepsia no local da punção com álcool iodado. Para punção da jugular, utilizou-se agulha 12 GA (12 x $3 \mathrm{~mm}$, Popper \& Sons $\left.{ }^{\circledR}\right)$ esterilizada com álcool 70\%. Após a punção, a cânula previamente autoclavada, que consistia em um tubo de silicone de $1,5 \mathrm{~mm}$ de diâmetro interno e $1,97 \mathrm{~mm}$ de diâmetro externo (Medicone ${ }^{\circledR}$ ) com $45 \mathrm{~cm}$ de comprimento, foi introduzida na jugular do animal através da agulha de canulação, de forma que $20 \mathrm{~cm}$ do seu comprimento permaneceu exposto. A seguir, a agulha de canulação foi retirada e uma agulha (40 x $12 \mathrm{~mm}$, com bisel aparado) foi inserida na porção externa da cânula e colada com Araldite ${ }^{\circledR}$ (a fim de permitir o acoplamento de uma seringa à cânula) e fechada com um adaptador Luer Lok (B-D ${ }^{\circledR}$ ) com látex autovedante. Uma solução de citrato de sódio $3,5 \%$ ( $1 \mathrm{~mL}$ em solução de $\mathrm{NaCl}$ 0,9\%) foi injetada no interior da cânula para evitar coagulação do sangue.

No dia da coleta, todas as fêmeas canuladas foram conduzidas ao curral de manejo, contidas por um cabresto, sendo fornecido alimento volumoso e água ad libitum. Com uma seringa de $10 \mathrm{~mL}$ acoplada à cânula inserida na veia jugular aspirou-se $8 \mathrm{~mL}$ de sangue, depositando-se o conteúdo coletado em um tubo de vidro $(10 \mathrm{~mL})$ com $200 \mu 1$ de EDTA a $10 \%$ (em solução de $\mathrm{NaCl}$ $0,9 \%$ ), sendo posteriormente centrifugados a 3000 $\mathrm{x}$ g por $15 \mathrm{~min}$, a $4^{\circ} \mathrm{C}$. Posteriormente, o plasma de cada amostra foi transferido, com auxílio de pipetas Pasteur descartáveis, para seus respectivos microtubos graduados (Scientific Specialties $\operatorname{Inc}^{\circledR}$ ) com $2 \mathrm{~mL}$ de capacidade e acondicionados a $-20^{\circ} \mathrm{C}$. As amostras permaneceram armazenadas até a realização do radioimunoensaio para a quantificação de GH. A quantificação hormonal foi feita com ensaios in house, realizados no Laboratório de
Endocrinologia Animal da UNESP, Campus de Araçatuba. O material (AFPB 55, NHPP - NIDDK) e os protocolos utilizados foram elaborados pelo Dr. A.F. Parlow (National Hormone \& Peptide Program, Harbor- University of California Los Angeles, CA, Torrance, USA). O coeficiente de variação interensaio, intraensaio e sensibilidade dos ensaios de $\mathrm{GH}$ foram, respectivamente, de $17 \%, 15 \%$ e 0,25 $\mathrm{ng} / \mathrm{mL}$. A porcentagem de ligação variou de 25 a $30 \%$.

Para identificação dos picos, área de secreção de GH e frequência e amplitude dos picos, utilizou-se o programa Prisma (GraphPad Prism versão 5.00 for Windows). A concentração de GH do pós-tratamento $(\mathrm{ng} / \mathrm{mL})$ foi calculada através da média dos valores obtidos no período pós-infusão do sulpiride (0 10h). Os picos foram identificados como aumentos duas vezes maiores que o coeficiente de variação intra-ensaio, envolvendo, pelo menos dois pontos. O programa calculou a área sob a curva e a área sob os picos, utilizando a regra trapezoidal, cuja unidade resultante foi o produto da multiplicação da concentração pelo tempo $[(\mathrm{ng} / \mathrm{mL}) \mathrm{min}]$. O período necessário para o aparecimento de pico foi determinado em função do momento (minutos) em que surgiu o maior pico. Os resultados foram submetidos à análise de variância, com medidas repetidas, empregando-se o programa SAS (System for Windows - SAS Institute Inc., Cary, NC, EUA, 1999-2000). As médias foram comparadas pelo teste de Duncan $(\mathrm{P} \leq 0,05)$. Antes de cada análise, os dados foram testados quanto à normalidade dos resíduos e à homogeneidade das variâncias. Os resultados foram expressos como média e erro padrão da média.

\section{Resultados}

A concentração média de GH foi maior no grupo Sulpiride quando comparado ao grupo Controle aos $8(10,10 \pm 0,38 \mathrm{ng} / \mathrm{mL}$ vs $4,3 \pm 0,34 \mathrm{ng} / \mathrm{mL}$; $\mathrm{P} \leq 0,05)$ e 12 meses de idade $(9,46 \pm 0,35 \mathrm{ng} / \mathrm{mL}$ vs $3,74 \pm 0,19 \mathrm{ng} / \mathrm{mL} ; \mathrm{P} \leq 0,05)$. Aos 16 meses de 
idade não foi observada diferença na concentração média de $\mathrm{GH}$ entre os grupos $(4,87 \pm 0,35$ vs $3,35 \pm$ $0,27 \mathrm{ng} / \mathrm{mL} ; \mathrm{P} \geq 0,05$; Figura 1a).

Nas novilhas do grupo Sulpiride a concentração média de GH foi maior aos 8 e 12 meses que aos 16 meses de idade $(10,10 \pm 0,38 \mathrm{ng} / \mathrm{mL}$ e 9,46 $\pm 0,35 \mathrm{ng} / \mathrm{mL}$ vs $4,87 \pm 0,35 \mathrm{ng} / \mathrm{mL} ; \mathrm{P} \leq 0,05)$, respectivamente. Não foi observado diferença $(\mathrm{P} \geq$ $0,05)$ no grupo Controle nos mesmos períodos $(4,3$ $\pm 0,34 ; 3,74 \pm 0,19$ e 3,35 $\pm 0,38 \mathrm{ng} / \mathrm{mL}$; Figura 1a). Em relação à área total de secreção (Figura 1b), área total de picos de GH (Figura 2a) e amplitude máxima dos picos de $\mathrm{GH}$ (Figura 3a) não houve diferença $(\mathrm{P} \geq 0,05)$ entre os grupos e dentro dos grupos nos períodos avaliados.

Figura 1. Média e erro padrão da média da (a) concentração média de GH, (b) área total de secreção de GH, póstratamento em novilhas Nelores pré-púberes que receberam solução salina (C) e que receberam sulpiride (S), em diferentes idades.
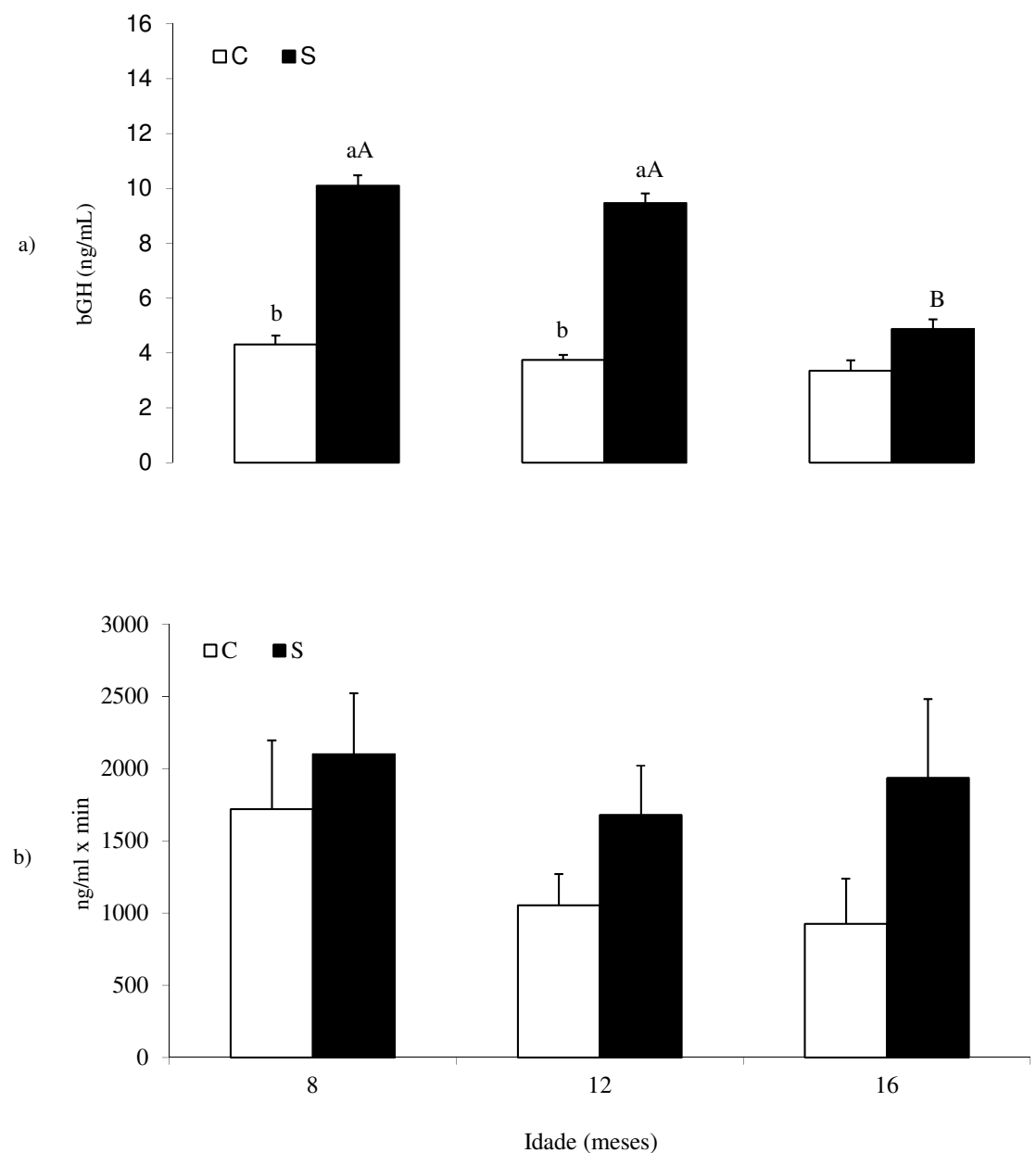

${ }^{\mathrm{AB}}$ Letras maiúsculas diferentes sinalizam diferença entre os meses em um mesmo grupo, pelo teste de Duncan $(\mathrm{P}<0,05)$.

${ }^{\mathrm{ab}}$ Letras minúsculas diferentes sinalizam diferença entre os grupos dentro de um mês, pelo teste de Duncan $(\mathrm{P}<0,05)$.

Fonte: Elaboração dos autores. 
Aos 8 meses de idade, o grupo Sulpiride apresentou menor tempo para aparecimento do primeiro pico de $\mathrm{GH}$ quando comparado ao grupo controle $(114 \pm 25,8 \mathrm{~min}$ vs $315 \pm 98,36 \mathrm{~min} ; \mathrm{P} \leq$ 0,05; Figura 2b). Entretanto, aos 12 meses, o grupo Sulpiride apresentou maior tempo em relação ao grupo Controle $(264 \pm 62,4 \mathrm{~min}$ vs $108 \pm 53,3$ min; $\mathrm{P} \leq 0,05)$. Aos 16 meses, não foi observada diferença entre os grupos no tempo necessário para o aparecimento do maior pico de $\mathrm{GH}$ ( $\mathrm{P} \geq 0,05$; Figura 2b). Aos 12 meses de idade, as novilhas do grupo Sulpiride (S) apresentaram maior tempo para aparecimento do primeiro pico, quando comparado aos 8 e 16 meses $(\mathrm{P} \leq 0,05$; Figura $2 b)$. Dentro grupo controle, foi observado menor tempo para ocorrência do primeiro pico de GH aos 12 meses de idade quando comparado aos 8 e 16 meses de idade $(\mathrm{P} \leq 0,05$; Figura 2b).

Após a administração de sulpiride o número de picos foi maior aos 16 meses de idade $(\mathrm{P}<0,05)$ quando comparado aos 8 e 12 meses de idade. (Figura 3b).

Figura 2. Média e erro padrão da média da (a) área total de picos de $\mathrm{GH}$ e (b) tempo necessário para o aparecimento do primeiro pico de GH em novilhas Nelore pré-púberes que receberam solução salina (C) e sulpiride (S), em diferentes idades.
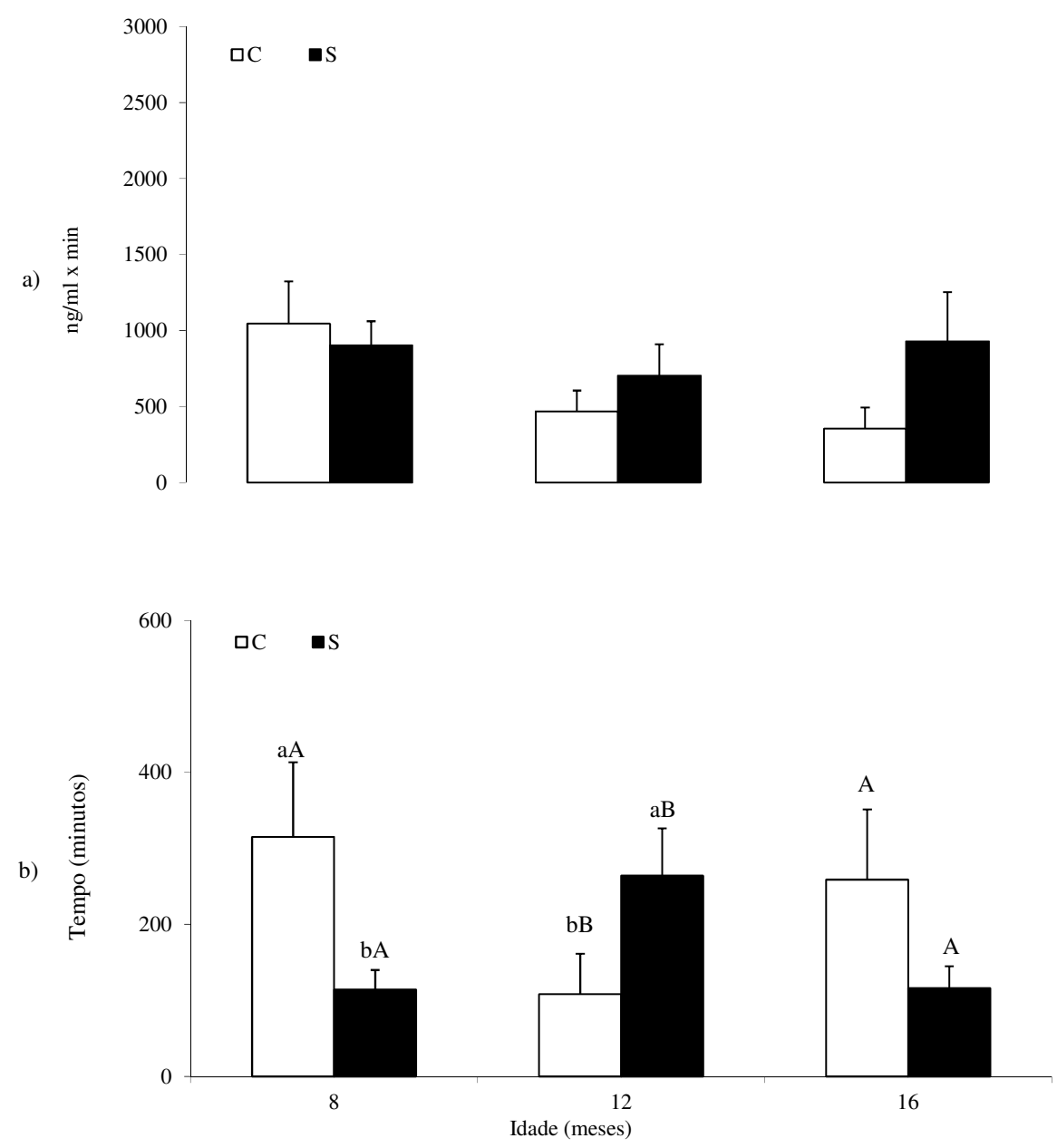

\footnotetext{
${ }^{\mathrm{AB}}$ Letras maiúsculas diferentes sinalizam diferença entre os meses em um mesmo grupo, pelo teste de Duncan $(\mathrm{P}<0,05)$.

${ }^{\text {ab }}$ Letras minúsculas diferentes sinalizam diferença entre os grupos dentro de um mês, pelo teste de Duncan $(\mathrm{P}<0,05)$.

Fonte: Elaboração dos autores.
} 
Figura 3. Média e erro padrão da média da (a) amplitude máxima dos picos de $\mathrm{GH}$ e (b) número de picos de secreção de GH em novilhas Nelore pré-púberes que receberam solução salina (C) e sulpiride (S), em diferentes idades.
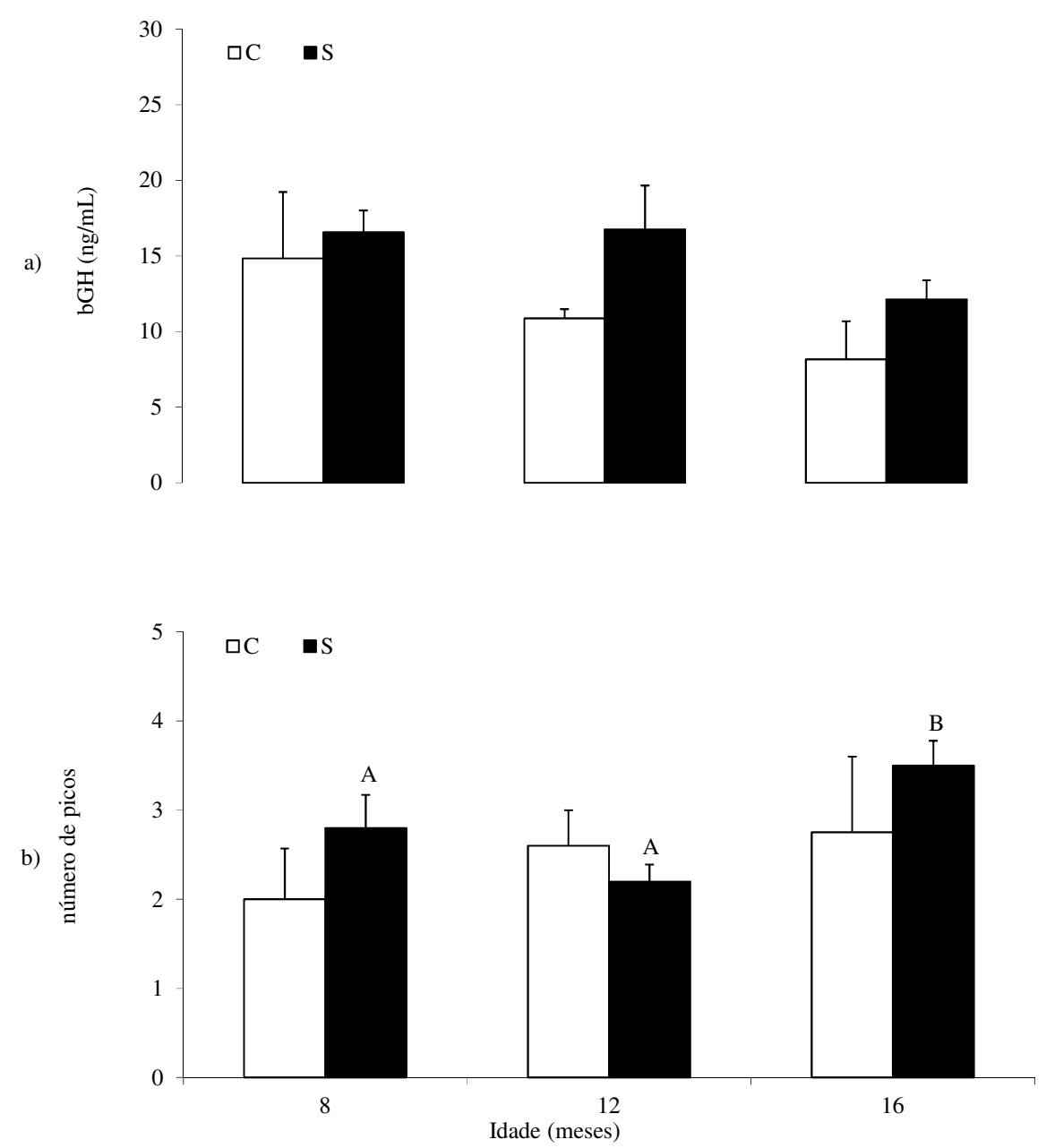

${ }^{\mathrm{AB}}$ Letras maiúsculas diferentes sinalizam diferença entre os meses em um mesmo grupo, pelo teste de Duncan $(\mathrm{P}<0,05)$.

Fonte: Elaboração dos autores.

\section{Discussão}

As vias dopaminérgicas têm papel no controle da secreção de GH em algumas espécies. Em ratos, por exemplo, estas estão envolvidas na secreção hipotalâmica de somatostatina, principal inibidor da secreção de GH (CHIHARA; ARIMURA; SCHALLY, 1979; KITAJIMA et al., 1989). Em ovinos, a dopamina inibiu a secreção basal de prolactina e GH em células de adenohipófise (RAY et al., 1986). Estudos em camundongos indicam que receptores D2 dopaminérgicos controlam a maturação do eixo somatotrófico (NOAIN et al., 2013).
No presente estudo, o efeito do sulpiride diminuiu com a idade no grupo tratado comparada ao grupo controle ao longo do tempo. O bloqueio da ação dopaminérgica com o uso de sulpiride (antagonista de receptor D2 dopaminérgico) promoveu aumento $(\mathrm{P}<0,05)$ na concentração média de $\mathrm{GH}$, aos $8 \mathrm{e}$ 12 meses de idade, comparado ao grupo Controle (Figura 1). No entanto, West et al. (1997) observaram que o bloqueio de receptores D2 dopaminérgicos não interferiu na liberação de somatostatina ou GHRH, sugerindo que a liberação de GH não envolve a ação em receptores D2 dopaminérgicos. 
Dados sugerem uma variação idade-dependente na densidade de receptores D1 e D2 em várias regiões cerebrais (SCHAMBRA et al., 1994). Os corte histológicos hipotalâmicos utilizados no experimento de West et al. (1997) foram obtidos de cérebros de bovinos com mais de 12 meses de idade e, no presente experimento com novilhas Nelore, foi observado que a concentração média de GH pós-tratamento com sulpiride aumentou apenas em período igual ou menor a 12 meses de idade comparada ao grupo controle. Aos 16 meses, não foi observada diferença na concentração de GH entre o grupo Sulpiride e Controle. Além disso, o efeito de um antagonista dopaminérgico pode ser dependente inclusive do modelo bioquímico utilizado (OLIVEIRA; REIMER; BRANDÃO, 2009). De acordo com a dose utilizada o sulpiride pode bloquear receptores D2 pré e pós-sinápticos (VASCONCELOS et al., 2007) ou somente receptores pós-sinápticos (WEST et al., 1997). Sendo assim, é possível que no período avaliado ( 8 e 12 meses, em relação aos 16 meses de idade) exista uma variação na sensibilidade dos receptores sensíveis à dopamina, promovendo aumento na concentração do hormônio do crescimento. Além desta possível variação da sensibilidade dos receptores, há também possivelmente uma variação na concentração de dopamina em relação à idade dos animais, o que também pode ter influenciado na ação do sulpiride. Em bovinos machos, a concentração de dopamina aumentou na área préóptica do hipotálamo da quinta para a décima semana de idade (RODRÍGUEZ et al., 1993) e na eminência média, dos 8 aos 12 meses de idade (DEAVER; BRYAN, 1999).

No presente trabalho, o uso do antagonista dopaminérgico aos 8 meses de idade reduziu o tempo para o primeiro pico, no entanto, aos 12 meses, aumentou o tempo para aparecimento do primeiro pico em relação ao grupo controle (Figura 2b). Aos 8 meses, a diminuição do tempo necessário para aparecimento do primeiro pico de secreção de $\mathrm{GH}$ sugere possível aumento na frequência de pulsos de secreção que não foi constatada no número de picos. No entanto, essa redução no tempo para o primeiro pico nos mostra que o sistema dopaminérgico aos 8 meses pode exercer sua ação inibitória sobre a secreção de GH tanto diminuindo sua concentração, como bloqueando o aparecimento do primeiro pico.

Aos 12 meses era esperado que o tempo para o primeiro pico também fosse menor para o grupo Sulpiride que para o controle, já que neste período foi observada maior concentração de GH com o uso do antagonista dopaminérgico. Entretanto, o tempo para aparecimento do primeiro pico foi maior no grupo Sulpiride. Os mecanismos de controle da secreção de GH podem envolver tanto o GHRH, que tem ação excitatória sobre a secreção deste hormônio, quanto à somatostatina, que apresenta ação inibitória. Com a maturação do eixo hipotálamo-hipófises provavelmente ocorrem mudanças no padrão do controle da secreção de $\mathrm{GH}$, podendo existir alternâncias de efeitos da dopamina.

O hormônio do crescimento é secretado em pulsos e o padrão de secreção pode variar dependendo do sexo, espécie e fotoperíodo (GAHETE et al., 2009). Apesar de a pulsatilidade ser controlada pelo hipotálamo, foi observado também cultura de somatotrófos apresentando secreção de GH púlsatil (HASSAN; MERKEL, 1994). A secreção episódica de GH pode ser alterada por diversos fatores do sistema nervoso central, da hipófise ou fatores periféricos (MCMAHON et al., 2001). Embora a somatostatina e o GHRH sejam os principais moduladores da secreção de $\mathrm{GH}$, outros neuropeptídios, neurotransmissores e neurohormônios alteram a secreção de GH indiretamente, agindo sobre a somatostatina e/ou hormônio liberador do hormônio do crescimento (MCMAHON et al., 2001).

$\mathrm{O}$ aumento no número de picos observado nos animais aos 16 meses pode ser consequência da aproximação da maturação do eixo hipotálamohipófise em relação aos animais aos 8 e 12 meses de idade. Um aumento na concentração de GH anterior 
a puberdade, altas concentrações na puberdade e um declínio pós-puberdade foram observados em novilhas búfalas (HALDAR; PRAKASH, 2006). No entanto, não foi observado aumento no número de picos no grupo Controle de novilhas da raça Nelore, o que sugere que o bloqueio da ação dopaminérgica neste período, com o uso do sulpiride, permitiu maior número de picos. Desta forma, o uso de um antagonista dopaminérgico sugere ação inibitória da dopamina sobre a secreção de $\mathrm{GH}$, evidenciado de diferentes formas: aumento na concentração média de GH aos 8 e 12 meses de idade e aumento no número de picos de secreção de $\mathrm{GH}$ aos 16 meses. Estes resultados diferem dos encontrados por Cardoso et al. (2009) que não observaram participação da dopamina como neurotransmissora na secreção de LH.

Aceitamos a hipótese de que a dopamina exerce ação inibitória sobre a secreção de $\mathrm{GH}$ ao longo da maturação sexual em novilhas da raça Nelore. Conclui-se que, com o uso do antagonista dopaminérgico sulpiride promoveu aumento na concentração de $\mathrm{GH}$ aos 8 e 12 meses de idade, com menor intensidade aos 16 meses de idade.

\section{Agradecimentos}

Fundação de Amparo à Pesquisa (FAPESP), \#2008-56680-1.

\section{Referências}

ADVIS, J. P.; WHITE SMITH, S.; OJEDA, S. R. Activation of growth hormone short loop negative feedback delays puberty in the female rat. Endocrinology, Los Angeles, v. 108, n. 4, p. 1343-1352, 1981.

AGUIAR, A. J. A. Contenção química de equinos e ruminantes. In: FEITOSA, F. L. F. Semiologia veterinária: a arte do diagnóstico. São Paulo: Roca, 2004. 807 p.

CARDOSO, D.; GUERRA, F. F.; BELTRAN, M. P.; PERRI, S. H. V.; NOGUEIRA, G. P. Sistema dopaminérgico na secreção de LH de novilhas Nelore. Revista Brasileira de Saúde e Produção Animal, Salvador, v. 10, n. 4, p. 980-987, 2009.
CARDOSO, D.; NOGUEIRA, G. P. Mecanismos neuroendócrinos envolvidos na puberdade de novilhas. Arquivos Ciências Veterinárias Zoologia Unipar, Umuarama, v. 10, n. 1, p. 59-67, 2007.

Participação do sistema adrenérgico na secreção de LH, em novilhas nelores pré-púberes. Revista Brasileira de Saúde e Produção Animal, Salvador, v. 9, n. 4, p. 839-847, 2008.

CHAGAS, L. M.; BASS, J. J.; BLACHE, D.; BURKE, C. R.; KAY, J. K.; LINDSAY, D. R.; LUCY, M. C.; MARTIN, G. B.; MEIER, S.; RHODES, F. M.; ROCHE, J. R.; THATCHER, W.W.; WEBB, R. Invited review: new perspectives on the roles of nutrition and metabolic priorities in the subfertility of high-producing dairy cows. Journal of Dairy Science, Champaign, v. 90, n. 9, p. 4022-4032, 2007.

CHELIKANI, P. K.; AMBROSE, D. J.; KEISLER, D. H.; KENELLY, J. J. Effects of dietary energy and protein density on plasma concentration of leptin and metabolic hormones in dairy heifers. Journal Dairy Science, Champaign, v. 92, n. 4, p. 1430-1441, 2009.

CHEUNG, C. C.; THORNTON, J. E.; KUIJPER, J. L.; WEIGLE, D. S.; CLIFTON, D. K.; STEINER, R. A. Leptin is a metabolic gate for the onset of puberty in the female rat. Endocrinology, Los Angeles, v. 138, n. 2, p. 855-858, 1997.

CHIHARA, K.; ARIMURA, A.; SCHALLY, A. V. Effect of intraventricular injection of dopamine, norepinephrine, acetylcholine, and 5- hydroxytryptamine on immunoreactive somatostatin release into rat hypohyseal portal blood. Endocrinology, Los Angeles, v. 104, n. 6, p. 1656-1662, 1979.

DEAVER, D. R.; BRYAN, K. A. Effects of exogenous somatotropin (ST) on gonadal function in ruminants and swine. Domestic Animal Endocrinology, Auburn, v. 17, n. 2-3, p. 287-297, 1999.

GAHETE, M. D.; DURÁN-PRADO, M.; LUQUE, R. M.; MARTÍNEZ-FUENTES, A. J.; QUINTERO, A.; GUTIERREZ-PASCUAL, E.; CÓRDOBA-CHÁCON, J.; MÁlAGON, M. M.; GRACIA-NAVARRO, F.; CASTAÑO, J. P. Understanding the multifactorial control of growth hormone reléase by somatotropes: lessons from comparative endocrinology. Annal of the New York Academy of Sciences, New York, v. 1163, p. 137-153, 2009.

HALDAR, A.; PRAKASH, B. S. Growth hormonereleasing factor (GRF) induced growth hormone advances puberty in female buffaloes. Animal Reproduction Science, Amsterdam, v. 92, n. 3-4, p. 254-267, 2006. 
HASSAN, H. A.; MERKEL, R. A. Perifusion model system to culture bovine hypothalamic slices in series with dispersed anterior pituitary cells. In Vitro Cellular \& Developmental Biology Animal, Berlim, v. 30, n. 7, p. 435-442, 1994.

HONARAMOOZ, A.; CHANDOLIA, R. K.; BEARD, A. P.; RAWLINGS, N. C. Opidoiergic, dopminergic and adrenergic regulation of LH secretion in prepubertal heifers. Journal of Reproduction and Fertility, Cambridge, v. 119, n. 2, p. 207-215, 2000.

KITAJIMA, N.; CHIHARA, K.; ABE, H.; OKIMURA, Y.; FUJI, Y.; SATO, M.; SHAKUTSUI, S.; WATANABE, M.; FUJITA, T. Effects of dopamine on immunoreactive growth hormone-releasing factor and somatostatin secretion from rat hypothalamic slices perifused in vitro. Endocrinology, Los Angeles, v. 124, n. 1, p. 69-76, 1989.

McMAHON, C. D.; RADCLIFF, R. P.; LOOKIGLAND, K. J.; TUCKER, H. A. Neuroregulation of growth hormone secretion in domestic animals. Domestic Animal Endocrinology, Auburn, v. 20, n. 2, p. 65-87, 2001.

MONTEIRO, F. M.; MERCADANTE, M. E. Z.; BARROS, C. M.; SATRAPA, R. A.; SILVA, J. A. V.; OLIVEIRA, L. Z.; SARAIVA, N. Z.; OLIVEIRA, C. S.; GARCIA, J. M. Reproductive tract development and puberty in two lines of Nellore heifers selected for postweaning weight. Theriogenology, New York, v. 80, n. 1, p. 10-17, 2013.

NOAIN, D.; PEREZ-MILLAN, M. I.; BELLO, E. P.; LUQUE, G. M.; CORDERO, R. C.; GELMAN, D. M.; PEPER, M.; TORNADU, I. G.; LOW, M. J.; BECÚVILALOBOS, D.; RUBINSTEIN, M. Central dopamine receptors regulate growth-hormone-dependent body growth and pheromone signaling to conspecific male. The Journal of Neuroscience, Washington, v. 33, p. 58345842, 2013.

OLIVEIRA, A. R.; REIMER, A. E.; BRANDÃO, M. L. Role of dopamine in the ventral tegmental area in conditioned fear. Behavioural Brain Research, Amsterdam, v. 199, p. 271-277, 2009.

PATTERSON, D. J.; WOOD, S. L.; RANDLE, R. F. Procedimentos que dão suporte ao manejo reprodutivo de novilhas de corte de reposição. In: NOVOS ENFOQUES NA PRODUÇÃO E REPRODUÇÃO DE BOVINOS, 10., 2006, Uberlândia. Curso... Uberlândia: [s.n], 2006. p. 106-127.
RAWLINGS, N. C.; EVANS, A. C. O.; HONARAMOOZ, A.; BARTLEWSKI, P. M. Antral follicle growth and endocrine changes in prebubertal cattle, sheep and goats. Animal Reproduction Science, Amsterdam, v. 78, n. 3-4, p. 259-270, 2003.

RAY, K. P.; GOMM, J. J.; LAW, G. J.; SIGOURNAY, C.; WALLIS, M. Dopamine and somatostatin inhibit forskolin-stimulated prolactin and growth hormone secretion but not stimulated cyclic AMP levels in sheep anterior pituitary cell cultures. Mollecular and Cellular Endocrinology, Amsterdam, v. 45, n. 2-3, p. 175-1822, 1986.

RODRÍGUEZ, R. E.; BENSON, B.; DUNN, A. N.; WISE, M. E. Age-related changes in biogenic amines, opiate, and steroid receptors in the pre-pubertal bull calf. Biology of Reproduction, New York, v. 48, n. 2, p. 371376, 1993.

SANTOS, J.E.P.; SÁ FILHO, M. F. Nutrição e reprodução em bovinos. In: SIMPÓSIO INTERNACIONAL DE REPRODUÇÃO ANIMAL APLICADA, 2., 2006, Londrina. Anais... Londrina: [s.n], 2006. p. 30-54.

SCHAMBRA, U. B.; DUNCAN, G. E.; BREESE, G. R.; FORNARETTO, M. G.; CARON, M. G.; FREMEAU JUNIOR, R. T. Ontogeny of D1 and D2 dopamine receptor subtypes in rat brain using in situ hybridization and receptor binding. Neuroscience, Oxford, v. 62, n. 1, p. $65-85,1994$.

VASCONCELOS, S. M. M.; LIMA, N. M.; SALES, G. T. M.; PATROCÍNIO, M. C. A.; OLIVEIRA, G. R.; SOUSA, F. C. F.; VIANA, G. S. B. Efeitos sulpirida sobre a densidade de receptores dopaminérgicos D2 símile em corpo estriado de ratos jovens e velhos, jovens e velhos. Pesquisa Médica, Fortaleza, v. 1, n. 4, p. 15-20, 2007.

WEST, C. R.; GAYNOR, P. J.; LOOKINGLAND, K. J.; TUCKER, H. A. Regulation of growth hormonereleasing hormone and somatostatin from perifused, bovine hypothalamic slices. I. Dopamine receptor regulation. Domestic Animal Endocrinology, Auburn, v. 14, n. 5, p. 334-348, 1997.

YELICH, J. V.; WETTEMANN, R. P.; MARSTON, T. T.; SPICER, L. J. Luteinizing hormone, growth hormone, insulin-like growth factor-I, insulin and metabolities before puberty in heifers fed to gain at two rates. Domestic Animal Endocrinology, Auburn, v. 13, n. 4, p. 325-338, 1996. 
